\title{
Article \\ Molecular Epidemiology of Rotavirus Strains in Symptomatic and Asymptomatic Children in Manhiça District, Southern Mozambique 2008-2019
}

\author{
Filomena Manjate ${ }^{1,2, * \mathbb{D}}$, Eva D. João ${ }^{1} \mathbb{D}$, Percina Chirinda ${ }^{1} \mathbb{D}$, Marcelino Garrine ${ }^{1,2} \mathbb{D}$, Delfino Vubil $^{1}$, \\ Nélio Nobela ${ }^{1}$, Karen Kotloff ${ }^{3}$, James P. Nataro ${ }^{4}$, Tacilta Nhampossa ${ }^{1,5}$, Sozinho Acácio ${ }^{1,5}$, Jacqueline E. Tate ${ }^{6}$, \\ Umesh Parashar $^{6}$, Jason M. Mwenda ${ }^{7}$, Pedro L. Alonso ${ }^{1,8,9}$, Martin Nyaga ${ }^{10} \mathbb{D}$, Celso Cunha ${ }^{2}$ and \\ Inácio Mandomando $1,5, * \mathbb{D}$
}

Citation: Manjate, F.; João, E.D.; Chirinda, P.; Garrine, M.; Vubil, D.; Nobela, N.; Kotloff, K.; Nataro, J.P.; Nhampossa, T.; Acácio, S.; et al Molecular Epidemiology of Rotavirus Strains in Symptomatic and Asymptomatic Children in Manhiça District, Southern Mozambique 2008-2019. Viruses 2022, 14, 134 https://doi.org/10.3390/v14010134 Academic Editors: Célia F. Rodrigues and Natália Cruz-Martins

Received: 1 December 2021 Accepted: 7 January 2022

Published: 12 January 2022

Publisher's Note: MDPI stays neutral with regard to jurisdictional claims in published maps and institutional affiliations.

Copyright: (C) 2022 by the authors. Licensee MDPI, Basel, Switzerland. This article is an open access article distributed under the terms and conditions of the Creative Commons Attribution (CC BY) license (https:// creativecommons.org/licenses/by/ $4.0 /)$.
1 Centro de Investigação em Saúde de Manhiça, Maputo 1929, Mozambique; eva.joao@manhica.net (E.D.J.); percina.chirinda@manhica.net (P.C.); marcelino.garrine@manhica.net (M.G.); delfino.vubil@manhica.net (D.V.); nelio.nobela@manhica.net (N.N.); tacilta.nhampossa@manhica.net (T.N.); sozinho.acacio@manhica.net (S.A.); alonsop@who.int (P.L.A.)

2 Global Health and Tropical Medicine (GHTM), Instituto de Higiene e Medicina Tropical (IHMT), Universidade Nova de Lisboa, 1349-008 Lisbon, Portugal; ccunha@ihmt.unl.pt

3 Center for Vaccine Development, University of Maryland School of Medicine, Baltimore, MD 21201, USA; Kkotloff@medicine.umaryland.edu

4 Department of Pediatrics, University of Virginia School of Medicine, Charlottesville, VA 22903, USA; jpn2r@virginia.edu

5 Instituto Nacional de Saúde, Ministério da Saúde, Marracuene 1120, Mozambique

6 Centers for Disease Control and Prevention, Atlanta, GA 30333, USA; jqt8@cdc.gov (J.E.T.); uap2@cdc.gov (U.P.)

7 African Rotavirus Surveillance Network, Immunization, Vaccines and Development Program, World Health Organization, Regional Office for Africa, Brazzaville P.O. Box 2465, Congo; mwendaj@who.int

8 ISGlobal, Hospital Clínic, Universitat de Barcelona, 08036 Barcelona, Spain

9 Global Malaria Program, World Health Organization, 1211 Geneva, Switzerland

10 Next Generation Sequencing Unit and Division of Virology, Faculty of Health Sciences, University of the Free State, Bloemfontein 9300, South Africa; NyagaMM@ufs.ac.za

* Correspondence: filomena.manjate@manhica.net (F.M.); inacio.mandomando@manhica.net (I.M.)

Abstract: Group A rotaviruses remain the leading cause of diarrhoea in children aged $<5$ years. Mozambique introduced rotavirus vaccine $\left(\right.$ Rotarix $\left.^{\circledR}\right)$ in September 2015. We report rotavirus genotypes circulating among symptomatic and asymptomatic children in Manhiça District, Mozambique, pre- and post-vaccine introduction. Stool was collected from enrolled children and screened for rotavirus by enzyme-immuno-sorbent assay. Positive specimens were genotyped for VP7 (G genotypes) and VP4 (P genotypes) by the conventional reverse transcriptase polymerase chain reaction. The combination G12P[8] was more frequently observed in pre-vaccine than in post-vaccine introduction, in moderate to severe diarrhoea $(34 \%, 61 / 177$ vs. $0, p<0.0001)$ and controls $(23 \%, 26 / 113$ vs. 0 , $p=0.0013)$ and mixed genotypes $(36 \%, 24 / 67$ vs. $7 \% 4 / 58, p=0.0003)$ in less severe diarrhoea. We observed changes in post-vaccine compared to pre-vaccine introduction, where G3P [4] and G3P[8] were prevalent in moderate to severe diarrhoea $(10 \%, 5 / 49$ vs. $0, p=0.0002$; and $14 \%, 7 / 49$ vs. $1 \%, 1 / 177, p<0.0001$; respectively), and in less severe diarrhoea $(21 \%, 12 / 58$ vs. $0, p=0.003$; and $24 \%, 14 / 58$ vs. $0, p<0.0001$; respectively). Our surveillance demonstrated the circulation of similar genotypes contemporaneously among cases and controls, as well as switching from pre- to postvaccine introduction. Continuous surveillance is needed to evaluate the dynamics of the changes in genotypes following vaccine introduction.

Keywords: rotavirus A; genotypes; case-control study; Mozambique 


\section{Introduction}

Group A rotaviruses (RVA) remain the predominant viral pathogen associated with diarrhoea in children aged $<5$ years, particularly in developing countries [1]. Globally, in 2016, RVA accounted for an estimated 258,173,300 episodes of diarrhoea, with 128,500 associated deaths, and the majority (up to $82 \%, \mathrm{~N}=104,733$ ) occurred in sub-Saharan Africa and South Asia [2]. RVA belongs to the Reoviridae family in the genus Rotavirus. It is a non-enveloped virus, with the genome structure of a double-stranded RNA (dsRNA) of 11 segments, composed of six structural (VP1-VP4, VP6 and VP7) and six non-structural proteins (NSP1-NSP6) [3]. RVA is commonly classified based on the binary system of two outer capsid structural proteins, VP7 (glycoprotein G) and VP4 (protease sensitive P), which can independently stimulate the production of neutralizing antibodies throughout infection $[4,5]$.

There are $41 \mathrm{G}(\mathrm{G} 1$ to $\mathrm{G} 41)$ and $57 \mathrm{P}(\mathrm{P}[1]$ to $\mathrm{P}[57])$ single genotypes already identified [6]. The most commonly prevalent global $\mathrm{G}$ and $\mathrm{P}$ combinations associated with diarrhoea are G1P[8], G2P[4], G3P[8], G9P[8] and G12P[8]. Additionally, rare combinations, G1P[6], G2P[6], G3P[6], G8P[4] and G9P [6], are also found [7-11]. In 2009, the World Health Organization (WHO) recommended the introduction of rotavirus vaccine into the immunization programs in all countries, especially those with high incidence of diarrhoea [2]. Vaccine introduction can be monitored through the implementation of surveillance systems to evaluate the trend of rotavirus burden on diarrhoeal diseases, as well as the dynamics of circulating genotypes (common or emerging) in distinct periods (pre- and post-vaccine introduction) [12,13].

Following WHO recommendations, in September 2015, Mozambique introduced the monovalent rotavirus vaccine, Rotarix ${ }^{\circledR}$ (GlaxoSmithKline Biologicals, Rixensart, Belgium), into its national immunization program. Data on rotavirus burden, prior to vaccine introduction in the country, is available from the previous enteric multicentre case-control study designated Global Enteric Multicenter Study (GEMS), conducted between 2007 and 2012 in three Asian countries and four sub-Saharan African countries, including Mozambique [14]. GEMS data revealed rotavirus, Cryptosporidium, enterotoxigenic Escherichia coli-producing heat stable toxin (ST-ETEC; with or without co-expression of heat-labile enterotoxin), and Shigella as the main pathogens associated with diarrhoea among all the sites. Particularly, in Mozambique (Manhiça District), rotavirus was the main pathogen associated with diarrhoea, with an attributable fraction of $35 \%$ and $20 \%$ in children aged $0-11$ months with moderate to severe (MSD) and less severe diarrhoea (LSD), respectively [14,15]. This supported the introduction of rotavirus vaccine in the national immunization program.

Therefore, to assess the impact of rotavirus vaccination on diarrhoeal hospitalizations and the prevalence of circulating genotypes, in 2015, we established the surveillance of rotavirus and other enteropathogens in children less than 5 years of age in Manhiça, within the context of diarrhoeal disease surveillance platform implementation at the Manhiça District Hospital and two other peripheral health centres across the district, among children under five years of age seeking care in these sentinel sites. Additionally, to assess the burden of the disease in the community, healthy community controls were enrolled as part of the diarrhoeal disease surveillance platform.

Sparse rotavirus genotype data are available in Mozambique, and mostly, they are from the pre-vaccine introduction period, showing that the combination G12P[8] was the most frequently detected combination in Gaza Province in 2011 [16], and G2P [4] predominated in Manhiça and Mavalane between 2012 and 2013 [17]. In addition, G3P[8] and G3P[4] were the most frequent combinations found in the post-vaccine introduction period in five sentinel sites in South, central and Northern regions of the country [18]. However, molecular data and rotavirus genotypes circulating, particularly in patients with mild symptoms and asymptomatic infections, have not yet been fully explored and remain scarce in Mozambique.

To assess the most common genotypes circulating in Manhiça District, and track possible shifting in rotavirus epidemiology and genotypes after the nationwide vaccine 
introduction, it is critical to monitor circulating strains and describe the impact of vaccine introduction. Thus, we aim to describe the distribution of rotavirus genotypes infecting children with diarrhoea (MSD and LSD) and their paired community controls, from pre (2008-2012) and post-vaccine (2016-2019) introduction in Manhiça District, Mozambique.

\section{Materials and Methods}

\subsection{Site Description}

Data from the pre-vaccine introduction are from the GEMS study, conducted from December 2007 to November 2012 by the Centro de Investigação em Saúde de Manhiça (CISM), at the Manhiça District Hospital (MDH) and six other peripheral health facilities (Maragra, Taninga, Ilha Josina, Nwamatibjana and Malavele), and in the households of the Manhiça community. Data from the post-vaccine introduction are from the diarrhoeal disease surveillance platform, from September 2015 to December 2019, from children recruited at $\mathrm{MDH}$ and two peripheral health facilities (Maragra and Xinavane) and the Manhiça community. Manhiça District is a rural area located $80 \mathrm{~km}$ north of Maputo Province in Southern Mozambique and has sub-tropical climate characteristics, with a predominance of two seasons, warm and rainy, observed between November and April, and cool and dry during the rest of the year [19]. The geographical and socio-demographic characteristics of the community have been described previously $[19,20]$.

CISM has been conducting a continuous demographic surveillance system (DSS) in the district since 1996, initially involving approximately 36,000 inhabitants [19]. During the GEMS study, the DSS study area had increased, covering 80,119 inhabitants from 20072010 and 89,617 inhabitants during 2011-2012 [19]. The diarrhoeal surveillance platform was established within a population of 169,990 inhabitants of the study area updated in 2014, while in 2019, there was an expansion of the DSS to the entire district, covering 201,845 inhabitants [20]. Within the DSS, data from births, migrations and deaths are periodically collected. CISM is adjacent to the MDH, and since 1997, the hospital and CISM have been performing a surveillance of all paediatric visits to the outpatient department (OPD), and admissions to the wards.

\subsection{Sample Collection}

The data presented in this analysis are from stool samples previously collected in children less than five years of age with MSD, LSD and community controls without diarrhoea, which tested positive for rotavirus by ELISA at the GEMS study and the diarrhoeal disease surveillance platform. GEMS started recruiting MSD and controls from 2007-2011, with the inclusion of LSD recruitment and their matched community controls in 2012. In the diarrhoeal disease surveillance platform, from September 2015 to April 2017, only MSD children were recruited to the study and from April 2017 to December 2019, there was inclusion of LSD and community controls for both MSD and LSD cases.

The definition of diarrhoeal cases (LSD and MSD), inclusion criteria for controls enrolment, sample collection, storage and processing at GEMS was previously described [14,21,22]. The diarrhoeal disease surveillance platform used the same criteria as GEMS for the enrolment of cases and controls. Briefly, children were recruited if they were admitted with diarrhoea, defined as three or more abnormal loose stools in $24 \mathrm{~h}$, requiring hospitalization and oral or intravenous rehydration for MSD cases definition. LSD cases consisted of children attended at the outpatient visits without criteria for hospitalization. The community controls for both MSD and LSD cases were randomly selected through the DSS system and were matched by age, sex and neighbourhood. Stool specimens from the health facility-based cases and community controls were collected in a container, kept on ice and sent immediately to the CISM laboratory for processing.

Diarrhoeal disease surveillance activities were interrupted from 2013 to 2014 and restarted in September 2015, coinciding with rotavirus vaccine introduction in Mozambique (September 2015). However, we considered the post-vaccine introduction period as January 2016, as the data from 2015 were sparse and it was also a transition year. 
Genotypes from MSD cases and controls in the pre-vaccine introduction period are from January 2008 to November 2012, and LSD are from 2012 only. In the post-vaccine introduction period among the diarrhoeal disease surveillance platform, only MSD cases (without matched controls) were included from January 2016 to April 2017, and from April 2017 to December 2019, MSD and LSD cases and respective controls were recruited.

\subsection{Laboratory Testing}

\subsubsection{Rotavirus Detection and RNA Extraction}

Stool samples from both studies were previously screened for rotavirus using a commercial ELISA kit (Prospect ${ }^{\circledR}$ Rotavirus, Oxoid, Ltd., Hampshire, UK) as described by the manufacturer. Positive samples for rotavirus were RNA extracted by QIAamp Viral RNA mini kit protocol (Qiagen, Hilden, Germany) and were stored at $-70^{\circ} \mathrm{C}$ until genotyping.

\subsection{2. cDNA Synthesis and PCR for Genotyping G and P Genes}

The same assay was used for genotyping the samples from GEMS and the diarrhoeal surveillance platform. Retrospective and prospective genotyping were performed, respectively. Briefly, $8 \mu \mathrm{L}$ of extracted RNA was reverse-transcribed to complementary DNA (cDNA) using consensus primer pairs Con2/Con3 for VP4 (P) [23], and sBeg9/End9 for VP7 (G) [24]. The cDNA product was then used as template for a multiplex semi-nested polymerase chain reaction (PCR) in conjunction with a cocktail of specific primers for each gene segment. The VP7 encoding gene was amplified using: G1, aBT1; G2, aCT2; G3, aET3 or mG3; G4, aDT4; G8, aAT8; G9, aFT9 or mG9; G12, G12b; G10, mG10 and the common primer RVG9 as previously described [25-27]. In parallel, the VP4 encoding gene was amplified with P[8], 1T-1D or 1T-1v; P[4], 2T-1; P[6], 3T-1; P[9], 4T-1; P[10], 5T-1; P[11], mp11; P [14], P4943 and Con3 as common primers, as previously described [24,28]. All PCR products were analysed by electrophoresis in $2.0 \%$ agarose gels, stained with $0.5 \mu \mathrm{g} / \mathrm{mL}$ ethidium bromide and visualized under ultraviolet illumination in a trans-illuminator imaging gel documentation system (Bio-Rad Laboratories, Hercules, CA, USA).

\subsection{Data Management and Statistical Analysis}

Data from the GEMS study were collected on specific study forms and included clinical and epidemiological risk factors and laboratory information. This information is available in one database (STATA version 14.0, StataCorp LP, Lakeway, TX, USA). Data from the diarrhoeal surveillance platform were collected on specific study forms and included clinical and epidemiological risk factors and laboratory information. Forms were checked for completeness before being double entered in the REDCap Program (version 6.17.2, Vanderbilt University, Nashville, TN, USA). All discrepancies in data entries were solved by referring to the original forms. The data analysis was performed using the statistical packages STATA version 14.1 (StataCorp LP, College Station, TX, USA) and R studios version 3.3.3 (Integrated Development for R. RStudio, PBC, Boston, MA, USA) for graphic projection. Genotype distribution was presented as absolute $(n)$ and relative frequencies $(\%)$, with the significance of differences in the proportions of the groups tested by chi-square or Fisher's exact tests as appropriate.

Due to the large number of genotypes in distribution and graphic representation, any single or combined genotype less than $1 \%$ as well as rare single or combined genotypes equal to one observation were classified and grouped as "others". We also created a group for any mixed G or P genotypes (more than one genotype in a single sample) as "mixed genotypes" and for partial G or P typed samples a group of "partial G/P types". The distribution of genotypes according to the age was determined based on the three age strata established at the GEMS study: 0-11 months, 12-23 months and 24-59 months of age.

The most common genotypes observed in the MSD cases were used to assess the distribution of the clinical severity score based on the Vesikari system [29], in pre- and post-vaccine introduction periods. The scores were summarized by absolute $(n)$ and relative frequencies $(\%)$ for nominal variables and median and standard deviation for continuous 
ones. The Kolmogorov-Smirnov test was used to observe the normality of quantitative variables. The significance of differences in proportion for nominal variables was estimated by chi-square or Fisher's exact tests when applicable and Kruskal-Wallis was used for comparisons, as an alternative to ANOVA for continuous variables. A significance level of $5 \%$ was considered for the whole analysis.

\section{Results}

3.1. Overview of Stool Collection and Rotavirus Group A Characterization between 2008 and 2019

During the period of January 2008-November 2012 (pre-vaccine introduction period) and January 2016-December 2019 (post-vaccine introduction period), 5353 stool samples were collected in GEMS and in the diarrhoeal surveillance platform, among children $<5$ years old with diarrhoea in the health centres and among ones without diarrhoea in the Manhiça community. The overall positivity of rotavirus in the pre-vaccine introduction period accounted for 29\% (393/1348) in MSD and LSD cases combined and 15\% (351/2411) in controls; positivity decreased in the post-vaccine introduction period, to $25 \%(141 / 559)$ in cases (MSD and LSD) and 11\% (113/1035) in controls (Table 1). About 89\% (888/998) of the positive samples were genotyped in both periods; $11 \%(110 / 998)$ were not possible to genotype due to insufficient amount of stool sample for testing.

Over the total genotyped samples, $43 \%$ (381/888) were fully typed $(\mathrm{G} / \mathrm{P})$, of them $50 \%$ $(192 / 381)$ in cases of MSD, 29\% (109/381) in cases of LSD and 21\% (80/381) in controls. At least $14 \%(126 / 888)$ of the samples were partially typed, with $25 \%(32 / 126)$ in cases of MSD, 13\% (16/126) in cases of LSD and 62\% (78/126) in controls; $43 \%(381 / 888)$ of the samples were non-typeable, $22 \%(84 / 381)$ of them in cases of MSD, $12 \%(45 / 381)$ in cases of LSD and 66\% (252/381) in controls. The non-typeable samples were excluded from the analysis.

Table 1. Overview of the number of collected stool samples and rotavirus group A detection among cases of MSD, LSD and controls in Manhiça District (Maragra, Manhiça District Hospital, Taninga, Ilha Josina, Nwamatibjana, Malavele and Xinavane), Mozambique, 2008-2012 and 2016-2019.

\begin{tabular}{|c|c|c|c|c|c|c|c|c|c|c|}
\hline & \multirow[b]{2}{*}{ Year } & \multicolumn{3}{|c|}{$\begin{array}{c}\text { Number of Samples } \\
\text { Collected N }\end{array}$} & \multicolumn{3}{|c|}{$\begin{array}{l}\text { Positive Samples for Rotavirus } \\
\text { ELISA } n(\%)\end{array}$} & \multicolumn{3}{|c|}{ Genotyped Samples $n(\%)$} \\
\hline & & MSD & LSD & Controls & MSD & LSD & Controls & MSD & LSD & Controls \\
\hline \multirow{5}{*}{$\begin{array}{l}\text { Pre-vaccine } \\
\text { introduction }\end{array}$} & 2008 & 343 & - & 344 & $85(25)$ & - & $18(5)$ & $56(66)$ & - & $9(50)$ \\
\hline & 2009 & 196 & - & 536 & 72 (37) & - & 90 (17) & $72(100)$ & - & $90(100)$ \\
\hline & 2010 & 143 & - & 416 & $46(32)$ & - & 95 (23) & $41(89)$ & - & $92(97)$ \\
\hline & 2011 & 102 & - & 299 & $43(42)$ & - & $54(18)$ & $38(88)$ & - & $42(78)$ \\
\hline & 2012 & 133 & $431^{1}$ & 816 & 49 (34) & $98(23)$ & $94(12)$ & 48 (98) & $96(98)$ & $91(97)$ \\
\hline \multirow[t]{2}{*}{ Subtotal } & - & 917 & 431 & 2411 & $295(32)$ & $98(23)$ & $351(15)$ & $255(86)$ & $96(98)$ & 324 (92) \\
\hline & $2016^{3}$ & 53 & - & - & $17(32)$ & _ & - & $17(100)$ & - & _ \\
\hline \multirow{3}{*}{$\begin{array}{l}\text { Post-vaccine } \\
\text { introduction }\end{array}$} & 2017 & 51 & $120^{2}$ & $372^{2}$ & $15(29)$ & $36(30)$ & $28(8)$ & $12(80)$ & $32(89)$ & $25(89)$ \\
\hline & 2018 & 69 & 167 & 492 & $16(23)$ & $30(18)$ & $50(10)$ & $16(100)$ & 29 (97) & $42(84)$ \\
\hline & 2019 & 52 & 47 & 171 & $13(25)$ & $14(29)$ & $35(20)$ & $10(77)$ & $13(92)$ & $17(49)$ \\
\hline Subtotal & - & 225 & 334 & 1035 & $61(27)$ & $80(23)$ & $113(11)$ & 55 (90) & $74(93)$ & $84(74)$ \\
\hline Total & _- & 1142 & 765 & 3446 & $356(31)$ & $178(23)$ & 464 (13) & 310 (87) & $170(96)$ & 408 (87) \\
\hline
\end{tabular}

\subsection{Distribution of Single G, P and Combined G-P Genotypes among Cases of MSD, LSD and Community Controls}

The characterization of rotavirus genotypes by groups (MSD, LSD and controls) evidenced that in the G-types, G12 was significantly higher in the pre-vaccine than post-vaccine 
introduction period in all the three groups MSD (50\%, 88/177 vs. 4\%, 2/49, $p<0.0001)$, LSD $(49 \%, 33 / 67$ vs. $9 \%, 5 / 58, p<0.0001)$, controls (39\%, 44/113 vs. $2 \%, 1 / 46, p<0.0001)$, while G3 and G9 were significantly more prevalent in all groups in the post-vaccine introduction period, MSD (both with $p<0.001)$, LSD $(p<0.0001$ and $p=0.0054)$ and controls $(p=0.0036$ and $p=0.0014$ ) (Table 2).

In the $\mathrm{P}$ types, $\mathrm{P}[8]$ was significantly more frequent during the pre-vaccine than postvaccine introduction period in $\operatorname{MSD}(57 \%, 101 / 177$ vs. 33\%, 16/49, $p=0.0042)$ and P[6] in $\operatorname{LSD}(34 \%, 23 / 58$ vs. $10 \%, 6 / 58, p=0.0031)$, while $\mathrm{P}[4]$ was significantly more frequent during the post-vaccine introduction than during the pre-vaccine introduction period in MSD (47\%, 23/49 vs. 15\%, 27/177, $p<0.0001)$ (Table 2$)$.

Regarding the combinations, G12P[8] was significantly more frequent in the prevaccine introduction than in the post-vaccine introduction period in MSD $(34 \%, 61 / 177$ vs. 0 , $p<0.0001)$ and controls $(23 \%, 26 / 113$ vs. $0, p=0.0013)$, while mixed genotypes $(35 \%, 24 / 67$ vs. $7 \%, 4 / 58, p=0.0003)$ and G12P[6] $(24 \%, 16 / 67$ vs. $2 \%, 1 / 58, p=0.0008)$ were significantly prevalent in LSD in the pre-vaccine than post-vaccine introduction period, respectively. G3P [4] was significantly more prevalent in MSD and LSD in the post-vaccine than in the pre-vaccine introduction period $(10 \%, 5 / 49$ vs. $0, p=0.0002 ; 20 \%, 12 / 58$ vs. $0, p<0.0001$ respectively); similarly, G3P[8] was significantly more prevalent in MSD and LSD in the post-vaccine than in the pre-vaccine introduction period $(14 \%, 7 / 49$ vs. $0, p=0.0002 ; 24 \%$, $14 / 58$ vs. $0, p<0.0001$ respectively) (Table 2 ).

Table 2. Rotavirus single G, P and combined G-P genotypes found in cases of MSD, LSD and controls in children < 5 years of age, in Manhiça (Maragra, Manhiça District Hospital, Taninga, Ilha Josina, Nwamatibjana, Malavele and Xinavane), Mozambique, 2008-2012 and 2016-2019.

\begin{tabular}{|c|c|c|c|c|c|c|c|c|c|}
\hline \multirow[b]{2}{*}{$\begin{array}{c}\text { G } \\
\text { Genotypes }\end{array}$} & \multicolumn{3}{|c|}{ MSD } & \multicolumn{3}{|c|}{ LSD } & \multicolumn{3}{|c|}{ Controls } \\
\hline & $\begin{array}{c}\text { Pre- } \\
\text { Vaccine } \\
\mathrm{N}=177 \\
(n \%)\end{array}$ & $\begin{array}{c}\text { Post- } \\
\text { Vaccine } \\
\mathrm{N}=49(n \%)\end{array}$ & $p$-Value & $\begin{array}{c}\text { Pre- } \\
\text { Vaccine } \\
\mathrm{N}=67 \\
(n \%)\end{array}$ & $\begin{array}{c}\text { Post- } \\
\text { Vaccine } \\
\mathrm{N}=58(n \%)\end{array}$ & $p$-Value & $\begin{array}{c}\text { Pre- } \\
\text { Vaccine } \\
\mathrm{N}=113 \\
(n \%)\end{array}$ & $\begin{array}{c}\text { Post- } \\
\text { Vaccine } \\
\mathrm{N}=43 \\
(n \%)\end{array}$ & $p$-Value \\
\hline G1 & $26(14)$ & $5(10)$ & 0.5666 & $2(3)$ & $7(12)$ & 0.1069 & $6(5)$ & $6(15)$ & 0.1404 \\
\hline G2 & 30 (17) & $10(21)$ & 0.7264 & $1(2)$ & $2(3)$ & 0.8993 & $7(6)$ & $1(2)$ & 0.5668 \\
\hline G3 & $1(1)$ & $15(31)$ & $<0.0001$ & 0 & $28(49)$ & $<0.0001$ & $5(4)$ & $9(21)$ & 0.0036 \\
\hline G9 & $1(1)$ & $9(18)$ & $<0.0001$ & $1(2)$ & $10(17)$ & 0.0054 & $4(4)$ & $9(21)$ & 0.0014 \\
\hline G12 & $88(50)$ & $2(4)$ & $<0.0001$ & 33 (49) & $5(9)$ & $<0.0001$ & 44 (39) & $1(2)$ & $<0.0001$ \\
\hline Others & $1(1)$ & $1(2)$ & 0.9089 & $1(2)$ & 0 & 1.0000 & 0 & $1(2)$ & 0.6145 \\
\hline $\begin{array}{c}\text { Mixed } \\
\text { genotypes }\end{array}$ & $12(6)$ & $2(4)$ & 0.7199 & $21(31)$ & $2(3)$ & 0.0002 & $12(11)$ & $1(2)$ & 0.1768 \\
\hline$G x^{1}$ & $18(10)$ & $5(10)$ & 1.0000 & $8(11)$ & $4(7)$ & 0.5156 & $35(31)$ & $15(35)$ & 0.7828 \\
\hline \multicolumn{10}{|l|}{$\begin{array}{c}\mathbf{P} \\
\text { genotypes }\end{array}$} \\
\hline $\mathrm{P}[4]$ & $27(15)$ & $23(47)$ & $<0.0001$ & $15(22)$ & $23(40)$ & 0.0577 & $14(12)$ & $7(16)$ & 0.7087 \\
\hline$P[6]$ & $37(21)$ & $4(8)$ & 0.0660 & $23(34)$ & $6(10)$ & 0.0031 & $30(27)$ & $6(14)$ & 0.1455 \\
\hline $\mathrm{P}[8]$ & $101(57)$ & $16(33)$ & 0.0042 & $15(22)$ & $25(43)$ & 0.0224 & 44 (39) & $15(35)$ & 0.7781 \\
\hline Others & $1(1)$ & $1(2)$ & 0.9089 & $1(2)$ & 0 & 1.0000 & $6(5)$ & $2(5)$ & 1.0000 \\
\hline $\begin{array}{c}\text { Mixed } \\
\text { genotypes }\end{array}$ & $5(3)$ & 0 & 0.5215 & 11 (17) & $2(3)$ & 0.0380 & $5(4)$ & $1(2)$ & 0.8860 \\
\hline$P[x]^{2}$ & $6(3)$ & $5(10)$ & 0.1126 & $2(3)$ & $2(4)$ & 1.0000 & $14(13)$ & $12(28)$ & 0.0372 \\
\hline
\end{tabular}


Table 2. Cont.

\begin{tabular}{|c|c|c|c|c|c|c|c|c|c|}
\hline & \multicolumn{3}{|c|}{ MSD } & \multicolumn{3}{|c|}{ LSD } & \multicolumn{3}{|c|}{ Controls } \\
\hline $\begin{array}{c}\text { G } \\
\text { Genotypes }\end{array}$ & $\begin{array}{c}\text { Pre- } \\
\text { Vaccine } \\
\mathrm{N}=177 \\
(n \%)\end{array}$ & $\begin{array}{c}\text { Post- } \\
\text { Vaccine } \\
\mathrm{N}=49(n \%)\end{array}$ & $p$-Value & $\begin{array}{c}\text { Pre- } \\
\text { Vaccine } \\
\mathrm{N}=67 \\
(n \%)\end{array}$ & $\begin{array}{c}\text { Post- } \\
\text { Vaccine } \\
\mathrm{N}=58(n \%)\end{array}$ & $p$-Value & $\begin{array}{c}\text { Pre- } \\
\text { Vaccine } \\
\mathrm{N}=113 \\
(n \%)\end{array}$ & $\begin{array}{c}\text { Post- } \\
\text { Vaccine } \\
\mathrm{N}=43 \\
(n \%)\end{array}$ & $p$-Value \\
\hline \multicolumn{10}{|l|}{$\begin{array}{l}\text { G/P combi- } \\
\text { nation }\end{array}$} \\
\hline G1P[4] & 0 & $2(4)$ & 0.0661 & $1(2)$ & $2(3)$ & 0.8993 & 0 & $1(2)$ & 0.6145 \\
\hline G1P[8] & $24(13)$ & $3(6)$ & 0.2414 & $1(2)$ & $4(7)$ & 0.2801 & $5(5)$ & $4(9)$ & 0.4335 \\
\hline G2P[4] & $12(6)$ & $10(21)$ & 0.0100 & 0 & $1(2)$ & 0.9422 & $4(3)$ & $1(2)$ & 1.0000 \\
\hline G2P[6] & $15(8)$ & 0 & 0.0743 & 0 & $1(2)$ & 0.9422 & $1(1)$ & 0 & 1.0000 \\
\hline G3P[4] & 0 & $5(10)$ & 0.0002 & 0 & $12(20)$ & 0.0003 & $1(1)$ & 0 & 1.0000 \\
\hline G3P[8] & $1(1)$ & 7 (14) & $<0.0001$ & 0 & $14(24)$ & $<0.0001$ & $1(1)$ & $2(5)$ & 0.3799 \\
\hline G9P[6] & 0 & $3(6)$ & 0.0091 & 0 & $3(5)$ & 0.1941 & 0 & $1(2)$ & 0.6145 \\
\hline G9P[8] & $1(1)$ & $5(10)$ & 0.0013 & $1(2)$ & $5(9)$ & 0.1499 & $2(2)$ & $4(9)$ & 0.0854 \\
\hline G12P[4] & $5(3)$ & $2(4)$ & 1.0000 & $5(7)$ & $4(7)$ & 0.0939 & $1(1)$ & 0 & 0 \\
\hline G12P[6] & $17(9)$ & 0 & 0.0512 & $16(24)$ & $1(2)$ & 0.0008 & $12(10)$ & 0 & 0.0590 \\
\hline G12P[8] & $61(34)$ & 0 & $<0.0001$ & $9(13)$ & 0 & 0.0108 & $26(23)$ & 0 & 0.0013 \\
\hline Others & $2(2)$ & 0 & 1.0000 & 0 & $1(2)$ & 0.9422 & $1(1)$ & $1(2)$ & 0.6145 \\
\hline $\begin{array}{c}\text { Mixed } \\
\text { genotypes }\end{array}$ & $15(9)$ & $2(4)$ & 0.468 & $24(35)$ & $4(7)$ & 0.0003 & $11(9)$ & $2(5)$ & 0.4825 \\
\hline $\begin{array}{c}\text { Partial G/P } \\
\text { types }\end{array}$ & $24(14)$ & $10(21)$ & 0.3366 & $10(15)$ & $6(10)$ & 0.6199 & $49(43)$ & $27(64)$ & 0.0466 \\
\hline
\end{tabular}

${ }^{1}$ Unable to determine G genotypes; ${ }^{2}$ Unable to determine P genotypes; MSD-moderate to severe diarrhoea; LSD-less severe diarrhoea; controls: healthy children from the community.

\subsection{Temporal Distribution of Rotavirus G/P Genotype Combinations in Cases of MSD, LSD and} Community Controls from 2008 to 2019

The yearly distribution of common and rare genotypes combinations is shown in Figure 1. In the pre-vaccine introduction period, G1P[8] $(62 \%, 18 / 29)$ was the most frequent combination in cases of MSD in 2008. In the following years, different combinations were recorded such as G12P[8] with 57\% (32/56) in 2009 and 89\% (24/27) in 2011, G2P[4] $(37 \%, 10 / 27)$ in 2010 , and G12P[6] $(32 \%, 12 / 38)$ in 2012. Still in MSD, in the post-vaccine introduction period in 2016 , most cases $(64 \%, 7 / 11)$ were only partially genotyped. Of the remaining specimens, 2 were mixed genotypes, 1 was G2P[4], and 1 was G3P[4]. With 33\% (4/12), G3P[4] was the most frequent combination in 2017 and G2P [4] $(50 \%, 8 / 16)$ in 2018 . Finally, in 2019, G9P [8] (50\%, 5/10) was the most frequent genotype among all detected genotypes in MSD.

In LSD cases, mixed infections $(36 \%, 24 / 67)$ such as G3/G12P [4] $(7 \%, 5 / 67)$, G8/G12P[4] and G3/G8/G12P [4] [6], with 4\% (3/67) each, were most frequently detected in 2012. G3P [4] $(40 \%, 10 / 25)$ in 2017, G3P [8] $(38 \%, 9 / 24)$ in 2018, and equal frequency of $22 \%(2 / 9)$ of G3P [8], G9P [8] and G9P[6] in 2019 were detected. G1P[8] $(67 \%, 2 / 3)$ was detected in controls in 2008, while G12P[8] with $41 \%(16 / 39)$ and $71 \%(10 / 14)$ was most frequent in 2009 and 2011, respectively. G2P[4] $(16 \%, 4 / 25)$ was more frequent in 2010, while G12P [6] $(25 \%, 8 / 32)$ and mixed infections $(25 \%, 8 / 32)$, such as G3/G12P [4] (13\%, $4 / 32$ ), were frequently detected in 2012. After the vaccine introduction period in controls, G1P [8] $(21 \%, 3 / 14)$ was detected in 2017, mixed genotypes $(11 \%, 2 / 19)$ in 2018 and G9P [8] $(20 \%, 2 / 10)$ in 2019. Additionally, in 2017, 2018 and 2019, partial G/P genotypes were more frequent with $57 \%(8 / 14), 74 \%(14 / 19)$ and $50 \%(5 / 10)$, respectively. 
Annual distribution of G/P Genotypes

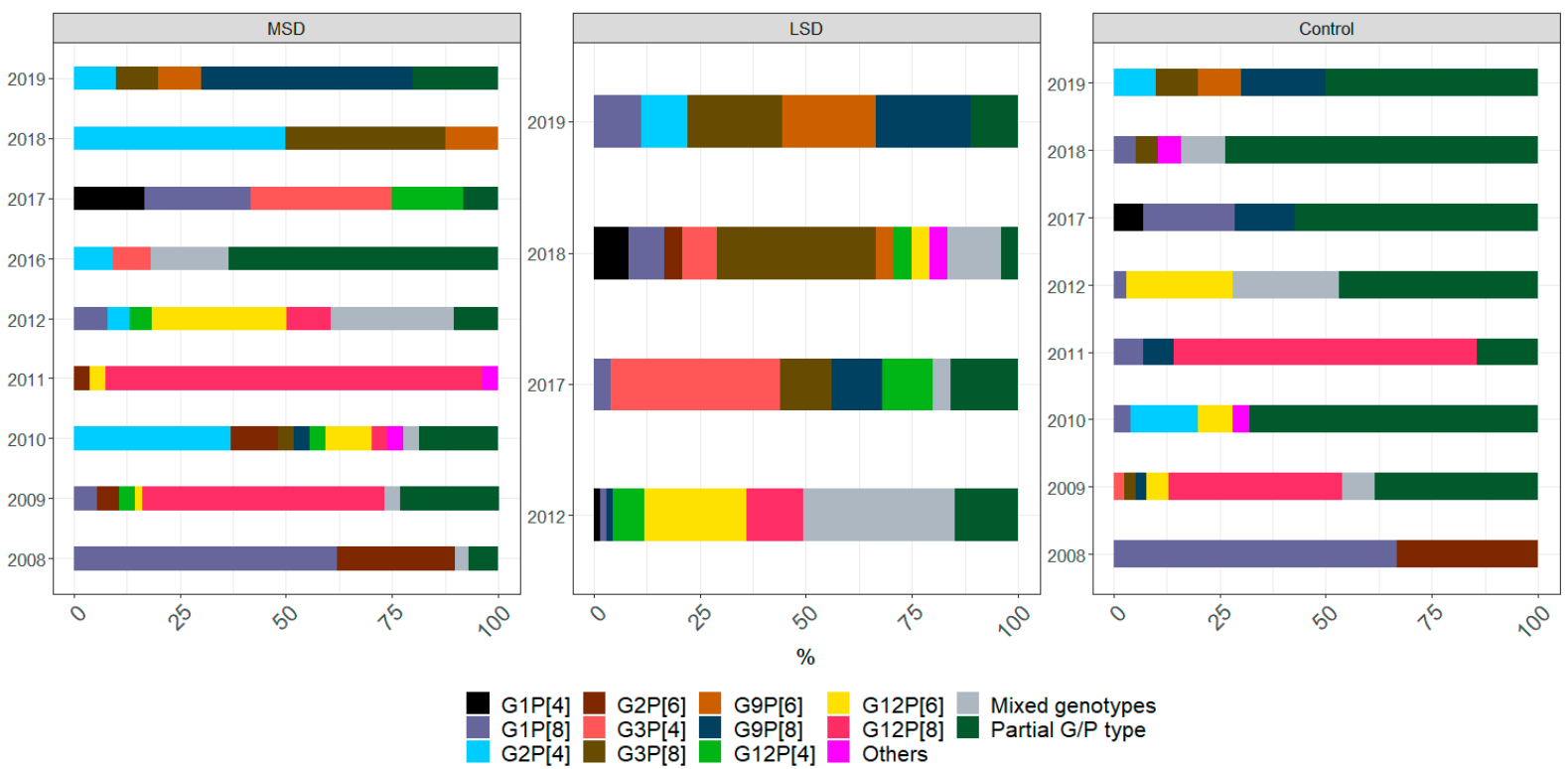

Figure 1. Temporal distribution of rotavirus genotype combinations found in cases and controls in children $<5$ years of age, in Manhiça (Maragra, Manhiça District Hospital, Taninga, Ilha Josina, Nwamatibjana, Malavele and Xinavane), Mozambique. Data represent two periods, pre-vaccine introduction, January 2008-November 2012, and post-vaccine introduction, January 2016-December 2019. No data were collected in 2013 and 2014. Colours represent each genotype combination specified, which are presented as the proportion (\%) of a specific genotype combination among the total number of tested samples in each year for each group (MSD, LSD and controls). MSD—moderate to severe diarrhoea; LSD—less severe diarrhoea; controls: healthy children from the community.

\subsection{Rotavirus Genotype Distribution in MSD, LSD and Community Controls According to Age Strata}

In the pre-vaccine introduction period, G12P[8] was the most frequent combination in all the age strata in MSD, 0-11 months (38\%, 52/137), 12-23 months $(22 \%, 7 / 32)$ and 24-59 months $(25 \%, 2 / 8)$. In all the age strata from LSD, mixed infections were frequent, 0-11 months (33\%, 10/30), such as G3/G8/G12P[4] (20\%, 7/30), 12-23 months (35\%, 10/29), such as G3/G8/G12P[4]P[6] (14\%, 4/29), and 24-59 months (50\%, 4/8), such as G3/G12P[4] $(25 \%, 2 / 8)$. With regard to controls, G12P [8] was frequent in children from 0-11 months $(31 \%, 21 / 67)$ and $12-23$ months $(12 \%, 4 / 33)$, while mixed infections $(23 \%, 3 / 13)$, such as $\mathrm{G} 1 / \mathrm{G} 12 \mathrm{P}[8](8 \%, 1 / 13)$, were frequent in the age strata from 24 to 59 months of age.

Furthermore, in the post-vaccine introduction period, G3P[8] was frequent in the age strata from 0 to 11 months in MSD (22\% 6/27) and LSD (37\%, 10/27), whereas G2P[4] and G9P[8], each with 19\% (3/16), were seen from 12 to 23 months in MSD. Equally, G2P[4] $(33 \%, 2 / 6)$ was found from 24 to 59 months in MSD. Among LSD, G3P[4] was frequent in all age strata, 0-11 months (15\%, 4/27), 12-23 months $(32 \%, 6 / 19)$ and $24-59$ months of age $(17 \%, 2 / 12)$. Nonetheless, in controls, $71 \%(10 / 14)$ of samples were partially typed in the age strata from 0 to 11 months; contrarily, G9P[8] (17\%, 4/23) was detected in children from 12 to 23 months, whereas from 24 to 59 months of age, the six samples available were partially typed (Figure S1).

\subsection{Clinical Characteristics of Disease in the Most Common Rotavirus Genotype Combinations} Found in MSD, in Pre-and Post-Vaccine Introduction Periods

Among the most commonly found G/P combined genotypes in MSD in the pre-vaccine introduction period, all children infected with G1P[8] (88\%, 21/24), G2P [4] (92\%,11/12), G2P[6] (100\%, 15/15), G12[6] (94\%, 16/17) and G12P[8] (95\%, 58/61) had >3 days duration of diarrhoea and $\geq 6$ episodes of diarrhoea in $24 \mathrm{~h}$. Additionally, children infected with all 
five genotypes (G1P [8], G2P[4], G2P[6], G12P[6], G12P[8]) had a longer vomiting duration, $\geq 3$ episodes per day $(p<0.05)$, and required intravenous rehydration, in the ascending order: $67 \%(16 / 24), 67 \%(10 / 15), 77 \%(47 / 61), 82 \%(14 / 17)$ and $83 \%(10 / 12)$, respectively (Table 3).

In the post-vaccine introduction period, we also observed that children infected with G2P [4], G3P [8], G9P [8] had diarrhoea for $>3$ days and these genotypes caused $>6$ episodes in $24 \mathrm{~h}$. Children infected with all the three genotypes (G2P[4], G3P [8], G9P[8]) suffered from vomiting with almost equal and high numbers of episodes ( $\geq 5$ in $24 \mathrm{~h})$ and needed intravenous dehydration: G2P [4] (100\%, 10/10), G3P [8] (100\%, (7/7), and G9P [8] (100\%, 4/4) (Table 3).

Table 3. Clinical characteristics of disease and rotavirus genotype combinations common in MSD cases, in the pre- and post-vaccine introduction periods 2008-2012 and 2016-2019, in Manhiça (Maragra, Manhiça District Hospital, Taninga, Ilha Josina, Nwamatibjana, Malavele and Xinavane), Mozambique, 2008-2012 and 2016-2019.

\begin{tabular}{|c|c|c|c|c|c|c|c|c|c|c|c|}
\hline \multirow[b]{2}{*}{$\begin{array}{l}\text { Clinical Char- } \\
\text { acteristics }\end{array}$} & \multirow[b]{2}{*}{ Categories } & \multicolumn{5}{|c|}{ Pre-Vaccine (January 2008-November 2012) } & \multirow[b]{2}{*}{$p$-Value } & \multicolumn{3}{|c|}{$\begin{array}{l}\text { Post-Vaccine (January } \\
\text { 2016-December 2019) }\end{array}$} & \multirow[b]{2}{*}{$p$-Value } \\
\hline & & $\begin{array}{c}\text { G1P }[8] \\
\mathrm{N}=24 \\
(n \%)\end{array}$ & $\begin{array}{c}\text { G2P[4] } \\
\mathrm{N}=12 \\
(n \%)\end{array}$ & $\begin{array}{l}\text { G2P[6] } \\
\mathrm{N}=15 \\
(n=\%)\end{array}$ & $\begin{array}{c}\mathrm{G} 12 \mathrm{P}[6] \\
\mathrm{N}=17 \\
n \%)\end{array}$ & $\begin{array}{c}\mathrm{G} 12 \mathrm{P}[8] \\
\mathrm{N}=61 \\
(n \%)\end{array}$ & & $\begin{array}{c}\mathrm{G} 2 \mathrm{P}[4] \\
\mathbf{N}=10 \\
(n \%)\end{array}$ & $\begin{array}{c}\text { G3P }[8] \\
\mathrm{N}=18 \\
(n \%)\end{array}$ & $\begin{array}{c}\text { G9P[8] } \\
\mathrm{N}=9 \\
(n \%)\end{array}$ & \\
\hline \multirow[t]{3}{*}{$\begin{array}{l}\text { Number of } \\
\text { days of } \\
\text { diarrhoea }\end{array}$} & 1-4 days & $21(88)$ & $11(92)$ & $15(100)$ & $16(94)$ & $58(95)$ & 0.656 & $9(90)$ & $16(88)$ & $9(100)$ & 1.000 \\
\hline & 5 days & $2(8)$ & 0 & 0 & 0 & $1(2)$ & & 0 & $1(6)$ & 0 & \\
\hline & $\geq 6$ & $1(4)$ & $1(8)$ & 0 & $1(6)$ & $2(3)$ & & $1(10)$ & $1(6)$ & 0 & \\
\hline \multirow[t]{3}{*}{$\begin{array}{l}\text { Maximum } \\
\text { number of } \\
\text { stools per day }\end{array}$} & $1-3$ & 0 & 0 & 0 & 0 & 0 & NA & 0 & 0 & $2(22)$ & 0.108 \\
\hline & $4-5$ & 0 & 0 & 0 & 0 & 0 & & $5(46)$ & $8(44)$ & $1(11)$ & \\
\hline & $\geq 6$ & $24(100)$ & $\begin{array}{c}12 \\
(100)\end{array}$ & 15 (100) & $\begin{array}{c}17 \\
(100)\end{array}$ & $61(100)$ & & $6(54)$ & $10(56)$ & $6(67)$ & \\
\hline \multirow[t]{3}{*}{$\begin{array}{c}\text { Duration of } \\
\text { vomiting } \\
\text { (days) }\end{array}$} & 1 & 0 & 0 & 0 & 0 & 0 & NA & $3(43)$ & $6(54)$ & 0 & 0.166 \\
\hline & 2 & 0 & 0 & 0 & 0 & 0 & & $4(57)$ & $5(46)$ & $3(75)$ & \\
\hline & $\geq 3$ & $18(75)$ & $9(75)$ & $13(93)$ & $\begin{array}{c}17 \\
(100)\end{array}$ & $61(100)$ & 0.044 & 0 & 0 & $1(25)$ & \\
\hline \multirow[t]{3}{*}{$\begin{array}{c}\text { Maximum } \\
\text { number of } \\
\text { episodes of } \\
\text { vomiting per } \\
\text { day }\end{array}$} & 1 & 0 & 0 & 0 & 0 & 0 & NA & $1(14)$ & $2(20)$ & 0 & 1.000 \\
\hline & $2-4$ & 0 & 0 & 0 & 0 & 0 & & $3(43)$ & $4(40)$ & $2(50)$ & \\
\hline & $\geq 5$ & 0 & 0 & 0 & 0 & 0 & & $3(43)$ & $4(40)$ & $2(50)$ & \\
\hline $\begin{array}{l}\text { Maximum } \\
\text { body } \\
\text { temperature } \\
\left({ }^{\circ} \mathrm{C}\right)\end{array}$ & mean (SD) & $\begin{array}{c}36.1 \\
( \pm 0.680)\end{array}$ & $\begin{array}{l}36.2 \\
( \pm 0.268)\end{array}$ & $\begin{array}{c}36.1 \\
( \pm 0.425)\end{array}$ & $\begin{array}{c}36.0 \\
( \pm 0.365)\end{array}$ & $\begin{array}{c}36.2 \\
( \pm 0.379)\end{array}$ & $0.121^{\#}$ & $\begin{array}{l}36.7 \\
(\mathrm{NA})\end{array}$ & $\begin{array}{c}36.7 \\
( \pm 15.13)\end{array}$ & $\begin{array}{l}36.6 \\
( \pm 0.089)\end{array}$ & 0.710 \\
\hline $\begin{array}{l}\text { Dehydration } \\
(\%)\end{array}$ & & 0 & 0 & 0 & 0 & 0 & NA & $1(100)$ & $7(54)$ & $5(100)$ & 0.517 \\
\hline $\begin{array}{l}\text { Oral } \\
\text { rehydration } n \\
(\%)\end{array}$ & & 0 & 0 & 0 & 0 & 0 & NA & $1(100)$ & $1(33)$ & 0 & 1.000 \\
\hline $\begin{array}{c}\text { IV rehydration } \\
n(\%)\end{array}$ & yes & $16(68)$ & $10(83)$ & $10(67)$ & $14(82)$ & $47(77)$ & 0.343 & $\begin{array}{c}10 \\
(100)\end{array}$ & $7(100)$ & $4(100)$ & NA \\
\hline
\end{tabular}




\section{Discussion}

This is one of the few studies in the sub-Saharan Africa region that analyses changes over time of rotavirus genotypes circulating over nine years and compares pre- and postvaccine periods. It shows a broad diversity of rotavirus genotype combinations and shift of the strains after the scale-up of rotavirus vaccine in Manhiça District, Mozambique. Strains found over the two study periods may represent those reported as common strains circulating regionally and worldwide [9]. We detected seven rotavirus G-types (G1, G2, G3, G4, G9, G10, G12), with G12 being the most frequent genotype in all groups, MSD, LSD and community controls in the pre-vaccine introduction period. Contrary to the post-vaccine introduction period, we observed a change of the most frequent G-types to G3 and G9 in MSD, LSD and controls. Our data also showed a decline of G1 in all groups, MSD, LSD and community controls from pre- to post-vaccine introduction periods, although not statistically significant. We found similar results when comparing available data from Mozambique [18], and reports from countries such as Bhutan, which had G12 in high frequency in the post-vaccine introduction period [30], and Malawi, which reported a high frequency of G3 in the post-vaccine introduction period [31].

Within VP4, P[6] was the most frequent in LSD and P[8] in MSD and controls in the pre-vaccine introduction period. This scenario remained until the post-vaccine introduction period, where $\mathrm{P}[8]$ was also recorded in high proportion in the three groups (MSD, LSD and controls). However, $\mathrm{P}[4]$ increased in proportion and was the most frequent genotype observed in LSD. The circulation of $\mathrm{P}[6]$ and $\mathrm{P}[8]$ has also been reported in high frequency elsewhere [32].

Among G/P combinations, G12P[8] was the most frequent in the pre-vaccine introduction period in MSD cases and controls. Conversely, G12P[6] was the most common combination in LSD. G12P[8] was also found to be the most frequent genotype circulating in Mozambique in 2011 in Gaza Province, while G12P[6] was most frequently detected in Maputo Province in 2012 and 2013 in the pre-vaccine introduction period [16,17]. Similar reports have shown G12P[8] as an important emerging combination worldwide, which reached a higher proportion than other common combinations [33,34]. By contrast, countries such as Ghana and Burkina Faso reported the circulation of G12P[8] after rotavirus vaccine introduction into their immunization programs $[35,36]$.

In the post-vaccine introduction period, G3P [8], G9P [8] and G3P [4] were most frequent in LSD and MSD, while G1P[8] was prevalent in controls, although not statistically significant. These results in our MSD cases are similar to those previously found in hospital-based studies in Mozambique, which also reported G3P[8] as the most frequent combination in MSD [18]. In addition, G3P[8] was also recorded as the most frequent combination in the post-vaccine introduction in other countries such as Fiji and India [37,38]. The dynamic change in the diversity of rotavirus genotypes, we observed in the post-vaccine introduction period in our study, may not explain whether this change is related to vaccine introduction in Mozambique, because genotypes shifting may occur in countries regardless of the implementation or not of vaccine into immunization programs, demonstrating a fluctuation of genotypes within and between countries [39].

Regarding the temporal distribution of rotavirus genotypes, we observed a switching and fluctuations of genotypes year after year. In the pre-vaccination period, G1P[8] was the most frequent combination in MSD cases and controls in 2008, while G12P[8] was predominant in 2009, 2011 and 2012. In LSD in 2012, G12P[6] was found to be more prevalent. Data on the predominance of G12P[8] we have reported since 2009 are different from other studies, such as the surveillance of rotavirus in Sicily since 1985, in which they did not report G12P[8] until 2012 [40]. Nevertheless, G12P[6] was predominantly seen in 2012 after vaccine introduction into six rotavirus surveillance sites in India [41].

In the post-vaccine introduction period, G3P [4] was the most frequent combination detected in MSD and LSD in 2016 and 2017, while G3P[8] was seen in LSD in 2018 and G9P [8] in MSD, LSD and controls in 2019. Our findings are in concordance with reports of African countries such as Botswana and Kenya in which G3P[4] was found after rotavirus 
vaccine introduction [42,43]. However, some studies reported G3P [8] in high frequency in cases of MSD in the post-vaccine introduction period in Mozambique [18] and other African countries such as Kenya reported G3P[8] and G9P[8] [44].

No major differences were observed in the distribution of genotypes by age in both pre- and post-vaccine introduction periods. Our findings from genotypes circulating in MSD in the age strata of 12-23 months are similar to the results of a surveillance of rotavirus report in Turkey before the introduction of the vaccine [45]. However, G9P[8] was reported in children older than 24 months of age in Seoul, Republic of Korea [46].

Evaluating the clinical characteristics, we observed that children infected with G1P[8], $\mathrm{G} 2 \mathrm{P}[4], \mathrm{G} 2 \mathrm{P}[6], \mathrm{G} 12 \mathrm{P}[6]$ and G12P[8] in the pre-vaccine and the combinations G2P[4], G3P [8] and G9P[8] in the post-vaccine introduction periods had diarrhoea for similar periods of $>3$ days. It is possible to hypothesize that these genotypes may cause the same disease severity. Genotypes from pre- (G1P[8], G2P [4], G2P[6], G12P[6] and G12P[8]) and post-vaccine (G2P[4], G3P [8] and G9P[8]) introduction periods are supposed to be related to severe diarrhoea symptoms as they cause more loss of stool per day ( $\geq 6)$. G1P[8], G2P[4], G2P[6], G3P[8], G9P[8], G12P[6] and G12P[8] are all likely to cause more frequent vomiting as well as dehydration. Previous studies associating genotypes with clinical symptoms in hospitalized children demonstrated that G12P[6] increased vomiting [47], G1P[8] was correlated with vomiting, dehydration and chronic disease [48], and G12P[8] was associated with dehydration and severity of the diarrhoea [49].

Partially typed strains, in general, constituted $62 \%$ of genotyped samples in our controls and with a significant proportion in cases of LSD (13\%); contrary to our results, data of rotavirus genotypes circulating before and after vaccine introduction in Eastern and Southern African countries (2010-2015) reported low proportions of partially typed strains over time, from $6.2 \%$ in 2010 to $9.1 \%$ in 2012 and a decrease to $4.3 \%$ in 2015 [50]. The significant proportion of partially typed samples, which we found in the control group, may be explained by the fact that controls may excrete less virus than children with more severe diarrhoea, as observed by other groups [51]. In addition to this, few available studies that investigated rotavirus on LSD cases have reported a high proportion of non-typeable strains [52,53]. A study in India reported $80 \%$ and another in China $24 \%$ [52,53]. Another study on LSD and community controls reported low viral loads from both groups (LSD and community controls) [51].

We reported a high frequency of non-typeable strains, one of the limitations of this study, which may represent a failure of the PCR technique or may be, in part, due to nucleotide substitutions at the primer-binding sites, or we may have new rotavirus strains circulating in Manhiça, which are not covered by the currently used primers based on the protocol of the World Health Organization for rotavirus genotyping, which uses the primer sets from the Gouvea et al., Gentsch et al. and other authors [24-28], similar to what was reported among rotavirus strains from the African Rotavirus Network [54]. A previous study of whole genome sequencing of partially typed strains from Manhiça (2012-2013) suggested that the G12 and P[4] specific genotyping primers (G12b and 2T-1, respectively) should be revised to prevent incorrect typing [55]. A study from Solberg and colleagues concluded that primer mismatch may be a widespread cause of genotyping failure and might be particularly problematic in countries with greater rotavirus diversity $[26,56]$. Hospital-based studies in Estonia and Indonesia have also reported a high proportion of non-typeable strains, $34 \%$ and $31 \%$, respectively $[57,58]$. Another study reported failure to detect mixed infections [59], while common genotypes (P[6], P[8] and G1) were undetectable [54].

The other limitation is related to the difference in the number of tested samples between the two periods. In some cases, there were small sample sizes for comparison. LSD was recruited after only one year (2012) in the pre-vaccine introduction period and in the post-vaccine introduction period, LSD and community controls were recruited after a year and half (2017) since the beginning (2015) of recruitment. The long-time break of the surveillance from pre- to post-vaccine introduction periods also limits the comparison due 
to unavailable samples from December 2012 to August 2015. Accordingly, we may have lost some important data regarding distribution of rotavirus genotypes early before the vaccine introduction. It also makes it difficult to attribute changes in genotype distribution to natural fluctuation, as vaccine impact on rotavirus circulating strains was difficult to assess. Despite the limitations, we were able to bring important data on the epidemiology of RVA infection in symptomatic and asymptomatic children in Manhica, and clinical presentation of MSD in each period (pre- and post-vaccine introduction periods). Although we found same genotypes circulating over the time in MSD, LSD and controls, to better investigate non-typeable strains, a new extraction protocol will be implemented to confirm the rotavirus RNA pattern (11-segmented genome) in an agarose gel electrophoresis. In addition, after rotavirus RNA pattern confirmation, we aim to apply whole genome sequencing as a genotyping strategy to characterize these strains.

\section{Conclusions}

We observed a high rotavirus genotype diversity and shift in the most genotype combinations among cases of MSD, LSD and community controls in both pre- and post-vaccine introduction periods in Manhiça District, Mozambique. Our data demonstrate circulation of similar genotypes among cases (MSD, LSD) and community controls, although it is necessary to carry out a whole genome analysis to assess whether these are the same genetic strains between symptomatic versus asymptomatic children, and the same analysis will be applied to non-typed strains for obtaining a more precise understanding of their genetic composition at the whole genome level and their evolutionary patterns. These results point out the importance of continuous surveillance of circulating rotavirus genotypes and its potential impact on the efficacy of currently administered vaccines in children, particularly in Mozambique in a rural setting such as Manhiça.

Supplementary Materials: The following supporting information can be downloaded at: https: / / www.mdpi.com/article/10.3390/v14010134/s1: Figure S1: Rotavirus genotypes distribution in MSD, LSD and community controls according to age strata.

Author Contributions: Conceptualization, F.M., E.D.J. and I.M.; methodology, F.M., E.D.J. and I.M.; software F.M.; validation, E.D.J. and I.M.; formal analysis, F.M.; investigation, F.M.; resources F.M. and E.D.J.; data curation, F.M., E.D.J. and I.M.; writing-original draft preparation, F.M., E.D.J. and I.M.; writing-review and editing, F.M., P.C., M.G., D.V., K.K., S.A., T.N., N.N., C.C., M.N., J.E.T., U.P., J.P.N., P.L.A., E.D.J. and I.M.; visualization, F.M. and E.D.J.; supervision, E.D.J. and I.M.; project administration, F.M. and E.D.J.; funding acquisition, K.K., I.M., T.N., P.L.A. and J.M.M. All authors have read and agreed to the published version of the manuscript.

Funding: The GEMS study was funded by the Bill \& Melinda Gates Foundation (OPP1033572) through the Center for Vaccine Development, USA. The surveillance of rotavirus and other enteropathogens in children less than 5 years of age in Manhiça was supported by GAVI through the Centers for Disease Control and Prevention (CDC), Atlanta, and the World Health Organization, Regional Office for Africa (WHO/AFRO), grant number MOA \#..870-15 SC; the United States Agency for International Development (USAID), grant number AID-656-F-16-00002 and Fundo Nacional de Investigação (FNI), Moçambique, grant number 245-INV, within the context of diarrhoeal disease surveillance platform implementation. F.M PhD is supported by Calouste Gulbenkian Foundation, grant number 234066 .

Institutional Review Board Statement: The National Bioethics Committee for Health (CNBS) of Mozambique approved the GEMS study protocol (reference 11/CNBS/07; IRB 00002657), 19 February 2007. The National Bioethics Committee for Health (CNBS) of Mozambique also approved the protocol of surveillance of rotavirus and other enteropathogens in children less than 5 years of age in Manhiça (reference 209/CNBS/15; IRB00002657), 22 July 2015. The ethical review board of IHMT NOVA has approved the project titled "Molecular and clinical epidemiology of rotavirus group A, in children less than 5 years of age, pre and post vaccine introduction, in a matched case-control study in Manhiça district, Mozambique, 2008-2019", with "parecer nr 8.21" of 21 July 2021, in which this manuscript was listed as one of the works to be included in the PhD thesis protocol of Filomena Manjate. 
Informed Consent Statement: Informed consent was obtained from all the children's parents/ caregivers; a written form was signed by literate parents/caregivers or a fingerprint for illiterate parents/caregivers.

Data Availability Statement: All relevant data are within the main text of the paper and in the Supplementary Materials.

Acknowledgments: The authors convey many thanks to all the caregivers who consented to their children's participation in both studies (GEMS and the diarrhoeal disease platform). They would also like to thank all the professionals in the hospitals and those on field recruitment for their full dedication and effort in children enrolment and collection of data and samples whenever possible.

Conflicts of Interest: The authors declare no conflict of interest. The funders had no role in the design of the study; in the collection, analyses, or interpretation of data, in the writing of the manuscript, or in the decision to publish the results.

\section{References}

1. Kompithra, R.Z.; Paul, A.; Manoharan, D.; Babji, S.; Sarkar, R.; Mathew, L.G.; Kang, G. Immunogenicity of a three dose and five dose oral human rotavirus vaccine (RIX4414) schedule in south Indian infants. Vaccine 2014, 32, A129-A133. [CrossRef] [PubMed]

2. Troeger, C.; Khalil, I.A.; Rao, P.C.; Cao, S.; Blacker, B.F.; Ahmed, T.; Armah, G.; Bines, J.E.; Brewer, T.G.; Colombara, D.V.; et al. Rotavirus Vaccination and the Global Burden of Rotavirus Diarrhea Among Children Younger Than 5 Years. JAMA Pediatr. 2018, 172, 958-965. [CrossRef]

3. Lin, C.-L.; Chen, S.-C.; Liu, S.-Y.; Chen, K.-T. Disease Caused by Rotavirus Infection. Open Virol. J. 2014, 8, 14-19. [CrossRef] [PubMed]

4. $\quad$ Moussa, A.; Fredj, M.B.H.; BenHamida-Rebaï, M.; Fodha, I.; Boujaafar, N.; Trabelsi, A. Phylogenetic analysis of partial VP7 gene of the emerging human group A rotavirus G12 strains circulating in Tunisia. J. Med. Microbiol. 2017, 66, 112-118. [CrossRef] [PubMed]

5. Patton, J.T. Rotavirus diversity and evolution in the post-vaccine world. Discov. Med. 2012, 13, 85-97.

6. Rotavirus Classification Working Group: RCWG. Available online: https://rega.kuleuven.be/cev/viralmetagenomics/virusclassification/rcwg (accessed on 22 April 2021).

7. Okitsu, S.; Hikita, T.; Thongprachum, A.; Khamrin, P.; Takanashi, S.; Hayakawa, S.; Maneekarn, N.; Ushijima, H. Detection and molecular characterization of two rare G8P[14] and G3P[3] rotavirus strains collected from children with acute gastroenteritis in Japan. Infect. Genet. Evol. 2018, 62, 95-108. [CrossRef] [PubMed]

8. Iturriza-Gómara, M.; Dallman, T.; Bányai, K.; Böttiger, B.; Buesa, J.; Diedrich, S.; Fiore, L.; Johansen, K.; Koopmans, M.; Korsun, N.; et al. Rotavirus genotypes co-circulating in Europe between 2006 and 2009 as determined by EuroRotaNet, a pan-European collaborative strain surveillance network. Epidemiol. Infect. 2011, 139, 895-909. [CrossRef]

9. Santos, V.S.; Marques, D.P.; Martins-Filho, P.R.S.; Cuevas, L.E.; Gurgel, R.Q. Effectiveness of rotavirus vaccines against rotavirus infection and hospitalization in Latin America: Systematic review and meta-analysis. Infect. Dis. Poverty 2016, 5, 1-12. [CrossRef]

10. Ouermi, D.; Soubeiga, D.; Nadembega, W.; Sawadogo, P.; Zohoncon, T.; Obiri-Yeboah, D.; Djigma, F.; Nordgren, J.; Simpore, J. Molecular Epidemiology of Rotavirus in Children under Five in Africa (2006-2016): A Systematic Review. Pak. J. Biol. Sci. 2017, 20, 59-69. [CrossRef]

11. Lestari, F.B.; Vongpunsawad, S.; Wanlapakorn, N.; Poovorawan, Y. Rotavirus infection in children in Southeast Asia 2008-2018: Disease burden, genotype distribution, seasonality, and vaccination. J. Biomed. Sci. 2020, 27, 1-19. [CrossRef]

12. Gupta, S.; Chaudhary, S.; Bubber, P.; Ray, P. Epidemiology and genetic diversity of group A rotavirus in acute diarrhea patients in pre-vaccination era in Himachal Pradesh, India. Vaccine 2019, 37, 5350-5356. [CrossRef] [PubMed]

13. Bucardo, F.; Nordgren, J. Impact of vaccination on the molecular epidemiology and evolution of group A rotaviruses in Latin America and factors affecting vaccine efficacy. Infect. Genet. Evol. 2015, 34, 106-113. [CrossRef] [PubMed]

14. Kotloff, K.L.; Nataro, J.P.; Blackwelder, W.C.; Nasrin, D.; Farag, T.H.; Panchalingam, S.; Wu, Y.; Sow, S.O.; Sur, D.; Breiman, R.F.; et al. Burden and aetiology of diarrhoeal disease in infants and young children in developing countries (the Global Enteric Multicenter Study, GEMS): A prospective, case-control study. Lancet 2013, 382, 209-222. [CrossRef]

15. Kotloff, K.L.; Nasrin, D.; Blackwelder, W.C.; Wu, Y.; Farag, T.; Panchalingham, S.; Sow, S.O.; Sur, D.; Zaidi, A.K.M.; Faruque, A.S.G.; et al. The incidence, aetiology, and adverse clinical consequences of less severe diarrhoeal episodes among infants and children residing in low-income and middle-income countries: A 12-month case-control study as a follow-on to the Global Enteric Multicenter Study (GEMS). Lancet Glob. Health 2019, 7, e568-e584. [CrossRef]

16. Langa, J.S.; Thompson, R.; Arnaldo, P.; Resque, H.R.; Rose, T.; Enosse, S.M.; Fialho, A.; de Assis, R.M.S.; da Silva, M.F.M.; Leite, J.P.G. Epidemiology of rotavirus A diarrhea in Chókwè, Southern Mozambique, from February to September, 2011. J. Med. Virol. 2016, 88, 1751-1758. [CrossRef]

17. João, E.D.; Strydom, A.; O’Neill, H.; Cuamba, A.; Cassocera, M.; Acácio, S.; Mandomando, I.; Motanyane, L.; Page, N.; De Deus, N. Rotavirus A strains obtained from children with acute gastroenteritis in Mozambique, 2012-2013: G and P genotypes and phylogenetic analysis of VP7 and partial VP4 genes. Arch. Virol. 2017, 163, 153-165. [CrossRef] 
18. João, E.; Munlela, B.; Chissaque, A.; Chilaúle, J.; Langa, J.S.; Augusto, O.; Boene, S.; Anapakala, E.; Sambo, J.; Guimarães, E.; et al. Molecular Epidemiology of Rotavirus A Strains Pre- and Post-Vaccine (Rotarix ${ }^{\circledR}$ ) Introduction in Mozambique, 2012-2019: Emergence of Genotypes G3P[4] and G3P[8]. Pathogens 2020, 9, 671. [CrossRef]

19. Sacoor, C.; Nhacolo, A.; Nhalungo, D.; Aponte, J.J.; Bassat, Q.; Augusto, O.; Mandomando, I.; Sacarlal, J.; Lauchande, N.; Sigaúque, B.; et al. Profile: Manhica Health Research Centre (Manhica HDSS). Int. J. Epidemiol. 2012, 42, 1309-1318. [CrossRef]

20. Nhacolo, A.; Jamisse, E.; Augusto, O.; Matsena, T.; Hunguana, A.; Mandomando, I.; Arnaldo, C.; Munguambe, K.; Macete, E.; Alonso, P.; et al. Cohort Profile Update: Manhiça Health and Demographic Surveillance System (HDSS) of the Manhiça Health Research Centre (CISM). Int. J. Epidemiol. 2021, 50, 395. [CrossRef]

21. Nhampossa, T.; Mandomando, I.; Acacio, S.; Quintó, L.; Vubil, D.; Ruiz, J.; Nhalungo, D.; Sacoor, C.; Nhabanga, A.; Nhacolo, A.; et al. Diarrheal Disease in Rural Mozambique: Burden, Risk Factors and Etiology of Diarrheal Disease among Children Aged 0-59 Months Seeking Care at Health Facilities. PLoS ONE 2015, 10, e0119824. [CrossRef]

22. Acácio, S.; Mandomando, I.; Nhampossa, T.; Quintó, L.; Vubil, D.; Sacoor, C.; Kotloff, K.; Farag, T.; Nasrin, D.; Macete, E.; et al. Risk factors for death among children 0-59 months of age with moderate-to-severe diarrhea in Manhiça district, southern Mozambique. BMC Infect. Dis. 2019, 19, 322. [CrossRef]

23. Gentsch, J.R.; Glass, R.I.; Woods, P.; Gouvea, V.; Gorziglia, M.; Flores, J.; Das, B.K.; Bhan, M.K. Identification of Group A Rotavirus Gene 4 Types by Polymerase Chain Reaction. J. Clin. Microbiol. 1992, 30, 1365-1373. [CrossRef]

24. Gouvea, V.; Glass, R.I.; Woods, P.; Taniguchi, K.; Clark, H.F.; Forrester, B.; Fang, Z.Y. Polymerase chain reaction amplification and typing of rotavirus nucleic acid from stool specimens. J. Clin. Microbiol. 1990, 28, 276-282. [CrossRef]

25. Iturriza Gómara, M.; Kang, G.; Mammen, A.; Jana, A.K.; Abraham, M.; Desselberger, U.; Brown, D.; Gray, J. Characterization of G10P[11] rotaviruses causing acute gastroenteritis in neonates and infants in Vellore, India. J. Clin. Microbiol. 2004, 42, $2541-2547$. [CrossRef] [PubMed]

26. Aladin, F.; Nawaz, S.; Iturriza, M.; Gray, J. Identification of G8 rotavirus strains determined as G12 by rotavirus genotyping PCR: Updating the current genotyping methods. J. Clin. Virol. 2010, 47, 340-344. [CrossRef]

27. Iturriza-Gómara, M.; Green, J.; Brown, D.W.; Desselberger, U.; Gray, J.J. Diversity within the VP4 Gene of Rotavirus P[8] Strains: Implications for Reverse Transcription-PCR Genotyping. J. Clin. Microbiol. 2000, 38, 898-901. [CrossRef] [PubMed]

28. Mphahlele, M.J.; Peenze, I.; Steele, A.D. Rotavirus strains bearing the VP4P[14] genotype recovered from South African children with diarrhoea. Arch. Virol. 1999, 144, 1027-1034. [CrossRef] [PubMed]

29. Vesikari, T.; Karvonen, A.; Prymula, R.; Schuster, V.; Tejedor, J.C.; Cohen, R.; Meurice, F.; Han, H.; Damaso, S.; Bouckenooghe, A. Efficacy of human rotavirus vaccine against rotavirus gastroenteritis during the first 2 years of life in European infants: Randomised, double-blind controlled study. Lancet 2007, 370, 1757-1763. [CrossRef]

30. Mhango, C.; Mandolo, J.J.; Chinyama, E.; Wachepa, R.; Kanjerwa, O.; Malamba-Banda, C.; Matambo, P.B.; Barnes, K.G.; Chaguza, C.; Shawa, I.T.; et al. Rotavirus Genotypes in Hospitalized Children With Acute Gastroenteritis Before and After Rotavirus Vaccine Introduction in Blantyre, Malawi, 1997-2019. J. Infect. Dis. 2020. [CrossRef] [PubMed]

31. Wangchuk, S.; Mitui, M.T.; Tshering, K.; Yahiro, T.; Bandhari, P.; Zangmo, S.; Dorji, T.; Tshering, K.; Matsumoto, T.; Nishizono, A.; et al. Dominance of Emerging G9 and G12 Genotypes and Polymorphism of VP7 and VP4 of Rotaviruses from Bhutanese Children with Severe Diarrhea Prior to the Introduction of Vaccine. PLoS ONE 2014, 9, e110795. [CrossRef]

32. Tiku, V.R.; Sharma, S.; Verma, A.; Kumar, P.; Raghavendhar, S.; Aneja, S.; Paul, V.K.; Bhan, M.K.; Ray, P. Rotavirus diversity among diarrheal children in Delhi, India during 2007-2012. Vaccine 2014, 32, A62-A67. [CrossRef] [PubMed]

33. Boni-Cisse, C.; Meite, S.; Mlan, A.B.; Zaba, F.; N'Guessan, R.; Lepri, N.A.; Lartey, B. Genotypic characterization of rotavirus in children under 5 years circulating in Côte D'Ivoire from 2010 to 2013. Virol. J. 2018, 15, 78. [CrossRef]

34. Motayo, B.O.; Faneye, A.O.; Adeniji, J.A. Epidemiology of Rotavirus A in Nigeria: Molecular Diversity and Current Insights. J. Pathog. 2018, 2018, 6513682. [CrossRef] [PubMed]

35. Lartey, B.L.; Damanka, S.; Dennis, F.E.; Enweronu-Laryea, C.C.; Addo-Yobo, E.; Ansong, D.; Kwarteng-Owusu, S.; Sagoe, K.W.; Mwenda, J.M.; Diamenu, S.K.; et al. Rotavirus strain distribution in Ghana pre- and post- rotavirus vaccine introduction. Vaccine 2018, 36, 7238-7242. [CrossRef] [PubMed]

36. Rönnelid, Y.; Bonkoungou, I.J.O.; Ouedraogo, N.; Barro, N.; Svensson, L.; Nordgren, J. Norovirus and rotavirus in children hospitalized with diarrhoea after rotavirus vaccine introduction in Burkina Faso. Epidemiol. Infect. 2020, 148, E245. [CrossRef]

37. Thomas, S.; Donato, C.; Covea, S.; Ratu, F.; Jenney, A.; Reyburn, R.; Khan, A.S.; Rafai, E.; Grabovac, V.; Serhan, F.; et al. Genotype Diversity before and after the Introduction of a Rotavirus Vaccine into the National Immunisation Program in Fiji. Pathogens 2021, 10, 358. [CrossRef]

38. Varghese, T.; Khakha, S.A.; Giri, S.; Nair, N.; Badur, M.; Gathwala, G.; Chaudhury, S.; Kaushik, S.; Dash, M.; Mohakud, N.; et al. Rotavirus Strain Distribution before and after Introducing Rotavirus Vaccine in India. Pathogens 2021, 10, 416. [CrossRef]

39. Hungerford, D.; Allen, D.J.; Nawaz, S.; Collins, S.; Ladhani, S.; Vivancos, R.; Iturriza-Gómara, M. Impact of rotavirus vaccination on rotavirus genotype distribution and diversity in England, September 2006 to August 2016. Eurosurveillance 2019, 24, 1700774. [CrossRef]

40. Giammanco, G.M.; Bonura, F.; DI Bernardo, F.; Cascio, A.; Ferrera, G.; Dones, P.; Saporito, L.; Collura, A.; Terranova, D.M.; Valenzise, M.; et al. Introduction and prolonged circulation of G12 rotaviruses in Sicily. Epidemiol. Infect. 2016, 144, 1943-1950. [CrossRef] [PubMed] 
41. Saluja, T.; Dhingra, M.S.; Sharma, S.D.; Gupta, M.; Kundu, R.; Kar, S.; Dutta, A.K.; Silveira, M.D.P.; Singh, J.V.; Kamath, V.G.; et al. Association of rotavirus strains and severity of gastroenteritis in Indian children. Hum. Vaccines Immunother. 2017, 13, 711-716. [CrossRef]

42. Gikonyo, J.N.U.; Mbatia, B.; Okanya, P.W.; Obiero, G.F.; Sang, C.; Steele, D.; Nyangao, J. Post-vaccine rotavirus genotype distribution in Nairobi County, Kenya. Int. J. Infect. Dis. 2020, 100, 434-440. [CrossRef]

43. Mokomane, M.; Esona, M.; Bowen, M.; Tate, J.; Steenhoff, A.; Lechiile, K.; Gaseitsiwe, S.; Seheri, L.; Magagula, N.; Weldegebriel, G.; et al. Diversity of Rotavirus Strains Circulating in Botswana before and after introduction of the Monovalent Rotavirus Vaccine. Vaccine 2019, 37, 6324-6328. [CrossRef]

44. Mwanga, M.J.; Verani, J.R.; Omore, R.; Tate, J.E.; Parashar, U.D.; Murunga, N.; Gicheru, E.; Breiman, R.F.; Nokes, D.J.; Agoti, C.N. Multiple introductions and predominance of rotavirus group a genotype G3P[8] in Kilifi, coastal Kenya, 4 years after nationwide vaccine introduction. Pathogens 2020, 9, 981. [CrossRef] [PubMed]

45. Durmaz, R.; Kalaycioglu, A.T.; Acar, S.; Bakkaloglu, Z.; Karagoz, A.; Korukluoglu, G.; Ertek, M.; Torunoglu, M.A.; Turkish Rotavirus Surveillance Network. Prevalence of Rotavirus Genotypes in Children Younger than 5 Years of Age before the Introduction of a Universal Rotavirus Vaccination Program: Report of Rotavirus Surveillance in Turkey. PLoS ONE 2014, 9, e113674. [CrossRef]

46. Shim, J.O.; Chang, J.Y.; Shin, S.; Moon, J.S.; Ko, J.S. Changing distribution of age, clinical severity, and genotypes of rotavirus gastroenteritis in hospitalized children after the introduction of vaccination: A single center study in Seoul between 2011 and 2014. BMC Infect. Dis. 2016, 16, 287. [CrossRef] [PubMed]

47. Laizāne, G.; Kīvīte, A.; Grope, I.; Smane, L.; Miklaševics, E.; Ozolina, L.; Gardovska, D. Clinical Characterisation of Rota Virus Infection Associated with Most Commonly Circulating Genotypes in Children Hospitalised in Children's University Hospital: A Cross-Sectional Study in Latvia. Proc. Latv. Acad. Sci. Sect. B. Nat. Exact Appl. Sci. 2019, 73, 312-316. [CrossRef]

48. Uzoma, E.B.; Chukwubuikem, C.; Omoyibo, E.; Tagbo, O. Rota virus genotypes and the clinical severity of Diarrhoea among children under 5 years of age. Niger. Postgrad. Med. J. 2016, 23, 1. [CrossRef]

49. Wardana, O.P.; Athiyyah, A.F.; Budiono, S.O.; Soegijanto, S. The Role of Rotavirus Genotype in the Severity of Acute Diarrhea in Children Under 5 Years Old at Surabaya, Indonesia. J. Hum. Virol. Retrovirol. 2015, 2, 1-5.

50. Seheri, L.; Magagula, N.; Peenze, I.; Rakau, K.; Ndadza, A.; Mwenda, J.; Weldegebriel, G.; Steele, A.; Mphahlele, M. Rotavirus strain diversity in Eastern and Southern African countries before and after vaccine introduction. Vaccine 2018, 36, 7222-7230. [CrossRef]

51. Kang, G.; Iturriza-Gomara, M.; Wheeler, J.G.; Crystal, P.; Monica, B.; Ramani, S.; Primrose, B.; Moses, P.D.; Gallimore, C.I.; Brown, D.W.; et al. Quantitation of Group A Rotavirus by Real-Time Reverse-Transcription-Polymerase Chain Reaction. J. Med. Virol. 2004, 73, 118-122. [CrossRef]

52. Tatte, V.S.; Chothe, N.S.; Chitambar, S.D. Characterisation of rotavirus strains identified in adolescents and adults with acute gastroenteritis highlights circulation of non-typeable strains: 2008-2012. Vaccine 2014, 32, A68-A74. [CrossRef]

53. Kuang, X.; Gong, X.; Zhang, X.; Pan, H.; Teng, Z. Genetic diversity of group A rotavirus in acute gastroenteritis outpatients in Shanghai from 2017 to 2018. BMC Infect. Dis. 2020, 20, 596. [CrossRef]

54. Esona, M.D.; Steele, D.; Kerin, T.; Armah, G.; Peenze, I.; Geyer, A.; Page, N.; Nyangao, J.; Agbaya, V.A.; Trabelsi, A.; et al. Determination of the G and P Types of Previously Nontypeable Rotavirus Strains from the African Rotavirus Network, 1996-2004: Identification of Unusual G Types. J. Infect. Dis. 2010, 202, S49-S54. [CrossRef]

55. Strydom, A.; João, E.D.; Motanyane, L.; Nyaga, M.M.; Potgieter, A.C.; Cuamba, A.; Mandomando, I.; Cassocera, M.; de Deus, N.; O'Neill, H.G. Whole genome analyses of DS-1-like Rotavirus A strains detected in children with acute diarrhoea in southern Mozambique suggest several reassortment events. Infect. Genet. Evol. 2019, 69, 68-75. [CrossRef]

56. Solberg, O.D.; Hasing, M.E.; Trueba, G.; Eisenberg, J.N. Characterization of novel VP7, VP4, and VP6 genotypes of a previously untypeable group A rotavirus. Virology 2009, 385, 58-67. [CrossRef]

57. Soeorg, H.; Tamm, E.; Huik, K.; Pauskar, M.; Mägi, D.; Pruudel, K.; Vainomäe, L.; Moosar, L.; Kirss, K.; Torm, S.; et al. Group A rotavirus genotypes circulating prior to implementation of a National Immunization Program in Estonia. Hum. Vaccines Immunother. 2012, 8, 465-469. [CrossRef] [PubMed]

58. Nirwati, H.; Wibawa, T.; Aman, A.T.; Wahab, A.; Soenarto, Y. Detection of group A rotavirus strains circulating among children with acute diarrhea in Indonesia. Springerplus 2016, 5, 1-6. [CrossRef] [PubMed]

59. Nyaga, M.M.; Jere, K.C.; Esona, M.D.; Seheri, M.L.; Stucker, K.M.; Halpin, R.A.; Akopov, A.; Stockwell, T.B.; Peenze, I.; Diop, A.; et al. Whole genome detection of rotavirus mixed infections in human, porcine and bovine samples co-infected with various rotavirus strains collected from sub-Saharan Africa. Infect. Genet. Evol. 2015, 31, 321-334. [CrossRef] [PubMed] 